\title{
Progress of molecular targeted therapy for head and neck cancer in clinical aspects
}

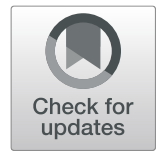

Kenji Nakano(1)

\begin{abstract}
Since the body's head and neck area affects many functions such as breathing, swallowing, and speaking, systemic treatments to head and neck cancer patients are important not only for survival but also for preserving functions and quality of life. With the progress that has been made in molecular targeted therapy, anti-EGFR antibody (cetuximab) and immune checkpoint inhibitors (nivolumab, pembrolizumab) have provided survival benefits to head and neck cancer patients and are approved for clinical practice. Clinical trials incorporating these new drugs for patients with locally advanced head/neck cancers are underway. However, the existing clinical evidence regarding molecular targeted drugs for head and neck cancers is based mostly on clinical trials allocated to squamous cell carcinoma patients. New targeted therapies for non-squamous cell carcinoma patients were recently reported, e.g., tyrosine kinase inhibitors for the treatment of thyroid cancers and HER2-targeted therapy for salivary gland cancers. With the goal of improving local control, molecular targeted treatment strategies as salvage local therapy are being investigated, including boron neutron capture therapy (BNCT) and near-infrared photoimmunotherapy (NIR-PIT). Herein the history and landscape of molecular targeted therapy for head and neck cancers are summarized and reviewed.
\end{abstract}

Keywords: Head and neck cancer, EGFR, PD-1, BNCT, Near-infrared photoimmunotherapy

\section{Introduction}

Head and neck cancers, which originate in the oropharynx, hypopharynx, larynx and other areas between the supraclavicular areas and skull base, account for approx. $3 \%$ of all malignant diseases, and squamous cell carcinoma (SCC) is the most common histology [1]. Smoking has long been known as a risk factor for SCC of the head and neck (SCCHN), and viral infections have been recognized as a risk factor of head and neck cancers; e.g., the relationships between human papilloma virus (HPV) and oropharyngeal cancer and between Epstein-Barr virus (EBV) and nasopharyngeal cancer $[2,3]$. The variety and risk factors of head and neck cancers are summarized in Fig. 1.

Approximately $60 \%$ of SCCHN patients are diagnosed at the locally advanced stage with complaints of neck swelling, hoarseness, difficulty in swallowing and more [1].

Correspondence: kenji.nakano@jfcr.or.jp

Department of Medical Oncology, Cancer Institute Hospital, Japanese

Foundation for Cancer Research, Ariake, Tokyo 135-8550, Japan
Curative surgical resection has been the standard treatment for SCCHN (with the exception of nasopharyngeal cancer), but this surgery can result in dysfunctions of swallowing, speaking, and even vision and hearing, and it can also cause cosmetic problems. There has been a great need for non-surgical treatment strategies that preserve the organ functions of the head and neck, and systemic chemotherapy and radiotherapy have thus been investigated as organ-preserving treatments.

Even when the primary lesion has been successfully treated, the cancers of some patients recur locally or metastatically, potentially resulting in death due to the cancer. The most common recurrence sites and events have been local or distant relapse, and lung, bone or liver metastases [4]. For relapsed/metastatic SCCHN patients, systemic chemotherapy is administered with the goal of survival improvement. The progress in molecular targeted therapy and cancer immunotherapy have extended the survival of SCCHN patients, particularly in the recurrent/metastatic setting. This review summarizes 
Risk factors

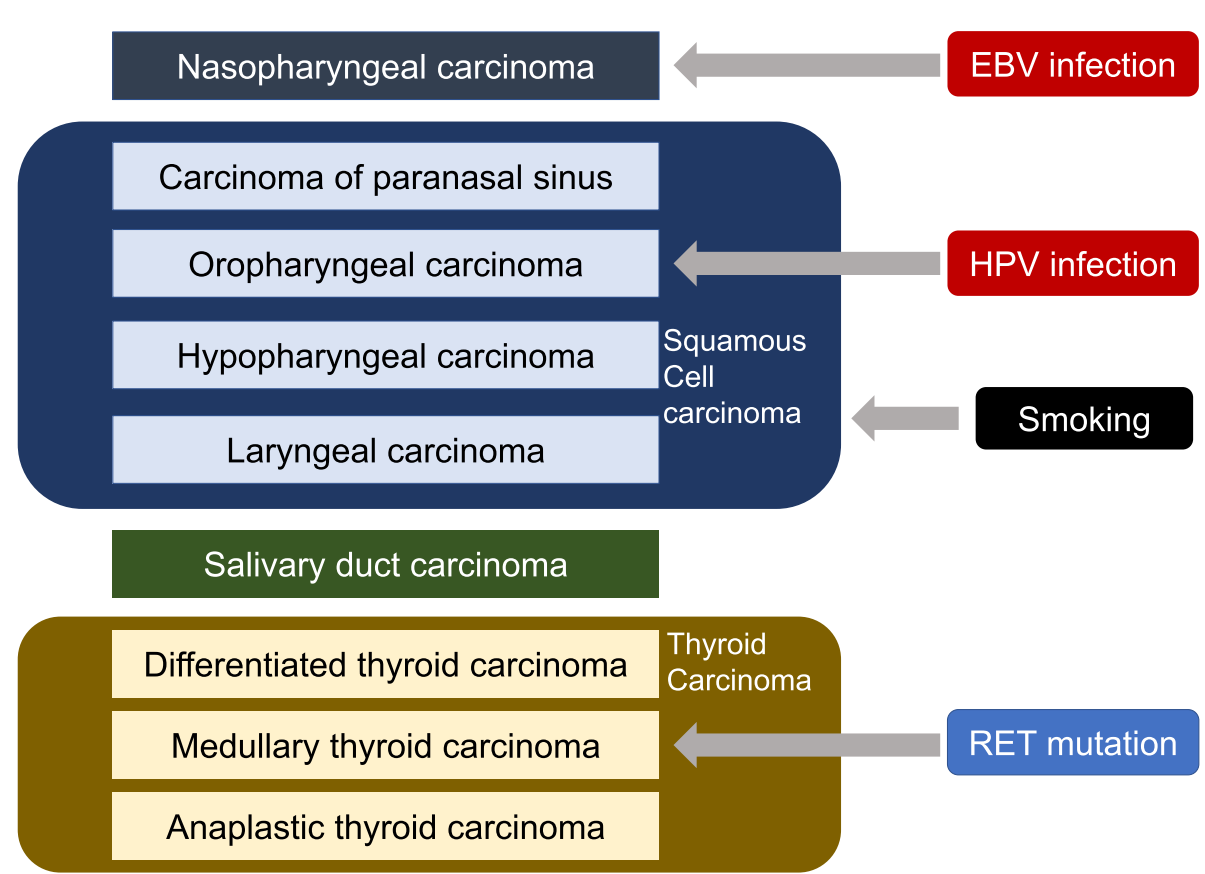

Fig. 1 The Variety and risk factors of head and neck cancers. Smoking is the most facous risk factor for Squamous cell carcinoma of the head and neck (SCCHN), and viral infections such as human papilloma virus (HPV) and Epstein-Barr virus (EBV) are known to be risk factors for specific head and neck cancers. In thyroid cancers, RET mutation is known to have a close relationship with medullary thyroid carcinoma

the development of molecular targeted therapy for head and neck cancer, focusing on the mechanisms underlying the treatment action and clinical role of each drug based on clinical evidence. The landscape of treatment strategy for head and neck cancer which would be discussed in the review, focusing SCCHN, was summarized in Fig. 2.

\section{Era of pre-molecular targeted therapy: cytotoxic chemotherapy}

Before the emergence of molecular targeted therapy, systemic therapies for SCCHN had been conducted using cytotoxic antitumor drugs in platinum-based regimens, and today platinum-based regimens remains

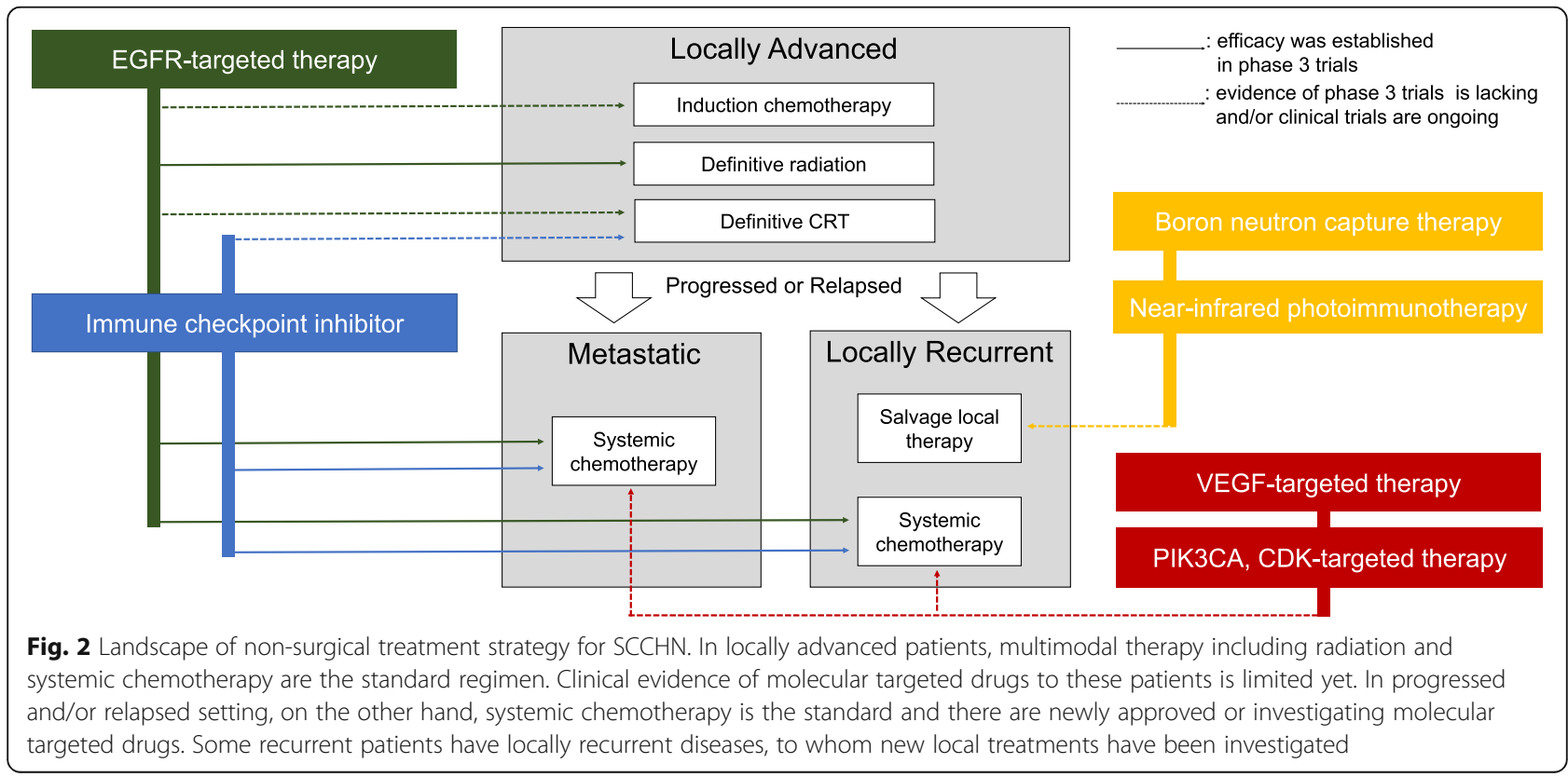


as the mainstream of systemic standard therapy for SCCHN $[4,5]$.

For patients with locally advanced SCCHN, systemic chemotherapy as an organ-preserving treatment strategy has replaced surgical resection and improved patients' survival; for example, the combination of cisplatin and 5fluorouracil (5-FU) for locally advanced laryngeal patients provided survival that was non-inferior to that afforded by surgery in a randomized clinical trial conducted in the 1990s [6]. The incorporation of systemic chemotherapy to enhance the synergy with radiation therapy is also being evaluated, and concurrent chemoradiotherapy (CRT) with high-dose cisplatin has been regarded as the standard non-surgical treatment for locally advanced SCCHN [7]. The clinical significance of CRT was also established for adjuvant settings after surgical treatment, especially for patients with positive surgical margins or extracapsular extension [8, 9]. The appropriate indications for and optimal treatment dose of cisplatin have been under investigation and remain a matter of controversy [10]. The addition of more cytotoxic therapy with induction chemotherapy and/or CRT has been tried, and three-drug combination chemotherapy with platinum, 5-FU, and taxane prolonged the patients' overall survival (OS) compared to two-drug chemotherapy (platinum and 5-FU) in a locally advanced setting $[11,12]$. However, the superiority of induction chemotherapy to CRT with cisplatin has not been established [13, 14].

For patients with recurrent/metastatic SCCHN, palliative systemic chemotherapy is the standard. Platinum is regarded as the key cytotoxic drug in this setting (as it is in locally advanced settings), and several cytotoxic agents with different mechanisms of action such as methotrexate and bleomycin as well as 5-FU and taxanes have been considered as candidates for palliative chemotherapy regimens [5]. Intensive combination chemotherapies were also considered for recurrent/metastatic settings [15-17], but although they showed high response rates these strategies provided limited clinical benefits in terms of survival. The performance status (PS) of SCCH $\mathrm{N}$ patients in a recurrent/metastatic setting is generally worse than that of patients in a local recurrent setting, and thus intensive cytotoxic therapy might result in the deterioration of patients' quality of life (QOL) in exchange for a temporary response. Sequential monotherapy applied to recurrent/metastatic SCCHN, especially as a second or later line of treatment, has been preferred considering patients' PS [5]. In general, the OS of recurrent/metastatic SCCHN patients has been approx. 6-9 months.

\section{EGFR-targeted therapy}

The era of molecular targeted therapy began at the start of the twenty-first century. Many molecular-targeted drugs were investigated and approved for the treatment of malignant diseases, including hematologic diseases and solid tumors. Epidermal growth factor receptor (EGFR) is one of promising molecular targets for treating solid tumors including SCCHN, as the activation of EGFR is observed in SCCHN [18]. With this rationale, many clinical trials of EGFR-targeted therapy for $\mathrm{SCCH}$ $\mathrm{N}$ were designed and performed.

\section{Cetuximab - the first molecular targeted drug for head and neck cancer}

Cetuximab is an EGFR-targeted monoclonal antibody that improved the OS of SCCHN patients in both locally advanced and recurrent/metastatic settings. The phase 3 IMCL-9815 (the Bonner trial) of locally advanced SCCH $\mathrm{N}$ patients compared radiotherapy with or without cetuximab [19]. The median OS was 49.0 months in the patients treated with cetuximab and 29.3 months in those not treated with cetuximab (hazard ratio [HR] 0.74, $p=0.03$ ) [19]. The phase 3 EXTREME trial of recurrent/metastatic SCCHN patients compared the efficacy of combination chemotherapy (5-FU + platinum) with cetuximab to that without cetuximab, and the OS was 10.1 months in the patients treated with cetuximab and 7.4 months in those not treated with cetuximab (HR $0.80, p=0.04)$ [20]. Based on these clinical data, cetuximab was approved in the U.S., the Europe and Japan for the treatment of SCCHN and has been used as the standard treatment option for SCCHN.

There are some unanswered questions regarding the appropriate use of cetuximab in clinical practice, especially for locally advanced SCCHN patients. In the Bonner trial, the superiority of cetuximab + radiotherapy (bioradiotherapy; BRT) compared to radiotherapy was observed, but the result of the trial did not include clinical data comparing BRT with CRT. After the Bonner trial, a randomized phase 2 trial (the TREMPLIN) comparing the efficacy of CRT and BRT for the treatment of SCCHN patients after induction chemotherapy revealed the non-inferiority of BRT [21], and another randomized phase $2 / 3$ trial (the $H \& N \quad 07$ trial) evaluated the efficacy of induction chemotherapy with CRT or BRT using four treatment arms; the results demonstrated the inferiority of BRT, though the trial was not designed to compare the statistical significance of CRT and BRT [22].

Considering the risk of platinum's cumulative toxicity (e.g., neurotoxicity), BRT after induction chemotherapy could be a reasonable treatment strategy. However, the current randomized phase 3 study (GORTEC 2007-02) failed to observe the superiority of induction chemotherapy followed by BRT compared to CRT [23]. The clinical benefit of the combination of CRT and BRT, i.e., radiotherapy with cisplatin and cetuximab, has also not been established. A phase 3 trial comparing CRT with or 
without cetuximab (the RTOG 0522 trial) did not show survival benefit by adding cetuximab, and this treatment combination resulted in higher rates of adverse events [24]. Another phase 3 study, the GORTEC 2007-01 trial, showed the improvement of progression-free survival (PFS) provided by BRT with cisplatin compared to BRT [25]. However, that trial's results did not confirm an improvement in the patients' OS, and the design of the GORTEC 2007-01 trial does not establish the benefit of adding cetuximab to CRT.

The clinical value of cetuximab is more firmly established in the recurrent/metastatic setting than in the locally advanced setting, but the balance of benefits and adverse events needs much more improvement. Adding cetuximab to cytotoxic chemotherapy involves some specific toxicities such as an acne-like rash, hypomagnesemia, and rarely interstitial lung disease [26-28]. Other combination regimens that are considered for patients who cannot tolerate the above-mentioned EXTREME regimen (5-FU + platinum) or who could be candidates for a replacement of the EXTREME regimen are thus being designed. The combination of taxane and cetuximab has provided some prospective data and showed high response rates $[29,30]$, and a carboplatin and taxane with cetuximab regimen also seems to be a beneficial combination [31].

The results of the phase 3 trials evaluating the efficacy of cetuximab to SCCHN were summarized in Table 1.

\section{EGFR inhibitors other than cetuximab}

There are many molecular targeted drugs Other than cetuximab that target the EGFR. Remarkable clinical benefits of the use of small tyrosine kinase inhibitors (TKIs) targeting the EGFR (e.g. gefitinib and erlotinib) have been observed in patients with non-small cell lung cancer (NSCLC) [32], but these TKIs did not show meaningful clinical efficacy against SCCHN [33, 34]. The efficacy of the second-generation TKI afatinib for the treatment of SCCHN was evaluated in several phase 3 trials in different settings, but none of the trials showed clinical benefits, preventing this TKI's approval for treating SCCHN [35-37]. The efficacy of another monoclonal EGFR antibody for treating SCCHN, i.e., panitumumab, was also evaluated in both locally advanced and recurrent/metastatic settings in clinical trials with designs that were similar to the trials of cetuximab $[38,39]$. Those trials failed to observe clinical benefits of panitumumab, similar to the cetuximab results.

\section{Predictive biomarkers of EGFR-targeted therapy}

EGFR-targeted antibodies including cetuximab are thought to bind with the EGFRs on the membrane of the tumor cells and have shown antitumor activity, but clinical analyses indicated that the amplification of the EGFRs in tumor membranes, at least those revealed by immunohistochemistry (IHC), is not a predictive factor of the antibody's effectiveness. Cetuximab was approved to treat colorectal cancer prior to its approval for head and neck cancer, and EGFR amplification revealed by IHC was originally considered an indication for the use of cetuximab or other EGFR-targeted antibodies. In clinical data however, the amplification of EGFR was not concordant with the clinical efficacy, and subsequent analyses revealed that the KRAS or other RAS mutations, which are located downstream of the EGFR signaling pathway, are more closely related to the efficacy of anti-EGFR antibodies as a negative biomarker [40, 41]. In SCCHN, the nonconcordance of EGFR amplification and the response to anti-EGFR therapy was also observed [42]. Unlike colorectal cancer, RAS mutations are rarely observed in SCCHN [43], but a 2017 report suggested that some KRAS variants in SCCHN might affect the efficacy of cetuximab or other antitumor drugs [44].

As discussed in the Introduction, HPV causes some SCCHNs (oropharyngeal carcinoma in particular). HPVrelated SCCHN is known to be more sensitive to cytotoxic chemotherapy and radiation therapy [45], and the efficacy of anti-EGFR therapy is also more prominent in HPV-related SCCHN patients [46, 47]. Whether the increase in the patients' response to cetuximab treatment in HPV-related SCCHN is more significant than the responses to other cytotoxic drugs is not yet known, and a phase 3 trial (RTOG 1016) comparing CRT to BRT in HPV-related SCCHN did not reveal the non-inferiority of BRT to CRT [48].

Table 1 The results of phase 3 trials evaluating the efficacy of cetuximab to SCCHN

\begin{tabular}{llllll}
\hline Trial & Patient setting & Treatment arm & OS Hazard ratio (95\% Cl) & $\boldsymbol{p}$-value & Reference \\
& Locally advanced & BRT vs Radiation & $0.74(0.57-0.97)$ & 0.03 & {$[19]$} \\
RTOG 0522 & Locally advanced & CRT with or without cetuximab & $0.95(0.74-1.21)$ & 0.32 & {$[24]$} \\
GORTEC 2007-01 & Locally advanced & BRT with or without cisplatin & $0.80(0.61-1.05)$ & 0.13 & {$[25]$} \\
GORTEC 2007-02 & Locally advanced & BRT with induction chemotherapy vs CRT & $1.12(0.86-1.46)$ & 0.39 & {$[23]$} \\
EXTREME & Recurrent/metastatic & Chemotherapy with or without cetuximab & $0.80(0.64-0.99)$ & 0.04 & {$[20]$} \\
\hline
\end{tabular}

*BRT: cetuximab with radiation. CRT: platinum-based chemotherapy with radiation 


\section{Immune checkpoint inhibitors}

One of the most important developments in cancer treatment is the emergence of immune checkpoint inhibitors, which have been incorporated in the standard treatment strategies in many malignant diseases such as lung cancer, gastrointestinal cancers, breast cancer, skin cancers, urological cancers, and more [49]. Immune checkpoint inhibitors target programmed death-1 (PD-1) and cytotoxic $\mathrm{T}$ lymphocyte antigen-4 (CTLA-4) on the host $\mathrm{T}$ cells or programmed death ligand-1 (PD-L1) on the tumor cells, which brings about the activation of $\mathrm{T}$ cells. The immune checkpoint inhibitors have been expected to be effective for treataing cancers with a high tumor mutation burden (TMB), and SCCHN is known to have a high TMB due to its relation to smoking [50]. Considering the clinical benefits of using immune checkpoint inhibitors for SCCHN, many clinical trials have been investigating several immune checkpoint inhibitors for SCCHN.

\section{Clinical evidence of immune checkpoint inhibitors' effects in head and neck cancer patients}

In a phase 3 trial (CheckMate-141) of SCCHN patients who were refractory to platinum-based chemotherapy, the anti-PD-1 antibody nivolumab provided OS that was superior to physicians' choices (cetuximab, docetaxel or methotrexate); the OS of the nivolumab arm was 7.5 months, and that of physicians' choices arms were 5.1 months (HR 0.70, $p=0.01$ ) [51]. In a similar setting (the KEYNOTE-040), the anti-PD-1 antibody pembrolizumab also tended to extend the patients' OS compared to the physicians' choices, although a significant improvement was not observed [52]. However, an OS benefit was established for pembrolizumab in an untreated recurrent/metastatic setting; in a randomized phase 3 trial (KEYNOTE-048) that compared pembrolizumab monotherapy, a pembrolizumab combination with platinum (cisplatin or carboplatin), and 5-FU to the EXTREME regimen, the pembrolizumab monotherapy, the combination with platinum (cisplatin or carboplatin), and 5-FU provided OS that was superior to that achieved in the EXTREME in PD-L1-positive patients, based on the combined positive score (CPS); the noninferiority of pembrolizumab monotherapy and its combination were also observed in the total patient population (Table 2) [53]. An anti-PD-L1 antibody that blocks PD-L1 on the surface of tumor cells is also being investigated for SCCHN management, but durvalumab, and anti-PD-L1 antibody which had already been approved to treat lung cancers $[54,55]$ did not succeed in showing a significant survival benefit for patients with recurrent/metastatic SCCHN in a phase 3 trial [56].

In addition to the recurrent/metastatic settings, the uses of immune checkpoint inhibitors for locally advanced SCCHN are under investigation. The induction of immune checkpoint inhibitors to locally advanced solid tumors is being investigated in many malignant diseases [57], and the safety of immune checkpoint inhibitors was shown in a single-arm clinical trial for the SCCHN oral cavity cancer [58]. It is considered that the combination of radiation therapy with immune checkpoint inhibitor might have adaptive potential, including so-called "abscopal effect" [59], so many clinical trials have been tried to confirm clinical benefit with the combination of radiotherapy and immune checkpoint inhibitors. Clinical trials of immune checkpoint inhibitors combined with radiation therapy were first performed for patients who were intolerable to cisplatin [60], and combinations of immune checkpoint inhibitors with CRT and BRT were subsequently examined $[61,62]$. The results of these trials indicated that the use of immune checkpoint inhibitors with CRT would be safe, but the efficacy of such regimens has not been established. The first phase 3 trial (JAVELIN Head \& Neck 100), which compared CRT with or without the antiPD-L1 antibody avelumab, failed to show the superiority of adding avelumab to CRT [63].

The results of phase 3 trials of immune checkpoint inhibitors to SCCHN other than KEYNOTE-048 were summarized in Table 3.

Table 2 The overall survival of the patients in the KEYNOTE-048 phase 3 trial comparing monotherapy with the anti-PD-1 antibody pembrolizumab and combination chemotherapy with cetuximab [53]

\begin{tabular}{llllllll}
\hline Treatment arm & Patients & OS $(\mathbf{9 5} \% \mathbf{C l})$ & OS of control $\mathbf{a r m}^{*} \mathbf{( 9 5 \% C l )}$ & HR $(\mathbf{9 5} \% \mathbf{C l})$ & $\boldsymbol{p}$-value & Significance & Confirmed result \\
\hline $\begin{array}{l}\text { Pembrolizumab } \\
\text { monotherapy }\end{array}$ & All & $11.6(10.5-13.6)$ & $10.7(9.3-11.7)$ & $0.85(0.71-1.03)$ & 0.0456 & HR $<1.2$ & Non-inferiority \\
& CPS $>1 \%$ & $12.3(10.8-14.9)$ & $10.3(9.0-11.5)$ & $0.78(0.64-0.96)$ & 0.0086 & 0.0109 & Superiority \\
& CPS $>20 \%$ & $14.9(11.6-21.5)$ & $10.7(8.8-12.8)$ & $0.61(0.45-0.83)$ & 0.0007 & 0.0024 & Superiority \\
Pembrolizumab & All & $13.0(10.9-14.7)$ & $10.7(9.3-11.7)$ & $0.77(0.63-0.93)$ & 0.0034 & 0.0041 & Superiority \\
combination & CPS $>1 \%$ & $13.6(10.7-15.5)$ & $10.4(9.1-11.7)$ & $0.65(0.53-0.80)$ & $<0.0001$ & 0.0026 & Superiority \\
& CPS $>20 \%$ & $14.7(10.3-19.3)$ & $11.0(9.2-13.0)$ & $0.60(0.45-0.82)$ & 0.0004 & 0.0023 & Superiority \\
\hline
\end{tabular}

*Combination chemotherapy with platinum (cisplatin or carboplatin), 5-FU and cetuximab. CPS: combined positive score 
Table 3 The results of phase 3 trials evaluating the efficacy of immune checkpoint inhibitors to SCCHN other than KEYNOTE-048

\begin{tabular}{|c|c|c|c|c|c|}
\hline Trial & Patient setting & Treatment arm & OS Hazard ratio $(95 \% \mathrm{Cl})$ & $p$-value & Reference \\
\hline JAVELIN Head \& Neck 100 & Locally advanced & CRT with or without Avelumab & $1.31(0.93-1.85)$ & 0.937 & {$[62]$} \\
\hline CheckMate 141 & $\begin{array}{l}\text { Recurrent/metastatic, } \\
\text { 2nd line }\end{array}$ & Nivolumab vs physicians' choice* & $0.70(0.51-0.96)$ & 0.01 & [51] \\
\hline KEYNOTE-040 & $\begin{array}{l}\text { Recurrent/metastatic, } \\
\text { 2nd line }\end{array}$ & Pembrolizumab vs physicians' choice & $0.80(0.65-0.98)$ & 0.0161 & {$[52]$} \\
\hline \multirow[t]{2}{*}{ EAGLE } & \multirow{2}{*}{$\begin{array}{l}\text { Recurrent/metastatic, } \\
\text { 2nd line }\end{array}$} & Durvalumab vs standard care ${ }^{* *}$ & $0.88(0.72-1.08)$ & 0.20 & \multirow[t]{2}{*}[56]{} \\
\hline & & $\begin{array}{l}\text { Durvalumab plus tremelimumab vs } \\
\text { standard care }\end{array}$ & $1.04(0.85-1.26)$ & 0.76 & \\
\hline
\end{tabular}

*Methotrexate, docetaxel or cetuximab. **Methotrexate, docetaxel, paclitaxel, cetuximab, 5-fluorouracil, TS-1 or capecitabine

The predictive markers of immune checkpoint inhibitors' effects

Immune checkpoint inhibitors have improved the outcomes of many cancer patients, but not all patients could benefit from them. Predictive biomarkers of immune checkpoint inhibitors (whether universal or specific to a given disease) have been pursued [64]. The most well-studied biomarker is the PD-L1 expression of tumor cells. PD-L1-positive patients have tended to be more sensitive to immune checkpoint inhibitors in many cancers, but the evaluation methods and/or the threshold for sensitivity have differed among the diseases [65, 66]. PD-L1-positive patients with SCCHN were reported to benefit from immune checkpoint inhibitors much more than those with other types of cancer. Based on the data of the KEYNOTE-048 trial of pembrolizumab, an evaluation of PD-L1 using the CPS criteria is recommended when selecting the treatment regimen, i.e., pembrolizumab monotherapy or a combination [53].

Unlike the scenario concerning cytotoxic drugs and EGFR inhibitors, it remains unknown whether a patient's HPV infection status affects the efficacy of immune checkpoint inhibitors for SCCHN. A sub-analysis of the CheckMate-141 phase 3 trial of nivolumab suggested that patients with HPV-related SCCHN have a better prognosis when treated with nivolumab [51], but the efficacy of pembrolizumab against HPV-related SCCHN seems no different from that in non HPV-related SCCH $\mathrm{N}$ patients $[53,67]$.

Other biomarkers related to cancer immune are being investigated [68], but an appropriate new marker that can be made available in clinical practice has not been established. From the clinical viewpoint, there is a report describing a difference in patient responses by the tumor lesion site (primary, lymph node metastasis, lung, or other distant metastases) [69].

\section{Therapy targeting non-squamous cell carcinoma}

Most head and neck cancers are SCC as mentioned above, but the other $10 \%$ of head and neck cancers has shown various histologies based on the primary organs in the head and neck area. Due to these carcinomas' rarity and diversity, the clinical evidence of the efficacy and safety of systemic therapies for non-squamous head and neck carcinomas has been insufficient. In clinical practice, head and neck cancers are often treated based on the treatment strategies for SCC. However, there is evidence that supports a specific approach to non-SCC head and neck cancers, and the progress of precision medicine and targeted therapy for these cancers continues.

\section{Nasopharnygeal carcinoma}

Nasopharyngeal carcinoma arises from the nasopharyngeal epithelium, and it is distinguished from other SCCHNs based on it anatomical and etiological factors. These tumors' origins are deep and adjacent to vital organs such as the eyes, ears and skull base, and thus surgical resection is not indicated. The etiology of nasopharyngeal carcinoma is highly related to EBV infection, and there are diverse differences in its incidence by geographic region: $>50 \%$ of nasopharyngeal carcinoma patients are diagnosed in east and southeast Asia [3]. These factors have resulted in nasopharyngeal carcinoma being excluded from many clinical trials of SCCHN, but on the other hand, there is evidence based on randomized clinical trials enrolling only nasopharyngeal carcinoma patients that indicates standard treatment strategies for nasopharyngeal carcinomas.

For locally advanced nasopharyngeal carcinomas, concurrent chemoradiotherapy with cisplatin is the standard, as for SCCHN. However, there are differences in the clinical significance of adjuvant chemotherapy prior to or after CRT; based on the 0099 phase 3 trial comparing the use of CRT after adjuvant chemotherapy with three courses of 5-FU and cisplatin to radiation-only in nasopharyngeal cancer patients [70], the addition of adjuvant chemotherapy remains the standard treatment, although a later randomized trial comparing CRT with adjuvant chemotherapy to CRT-only failed to show significant superiority of adjuvant chemotherapy [71]. Induction chemotherapy prior to CRT for nasopharyngeal cancer was investigated, and two randomized trials in which dose-adjusted TPF (taxane, platinum and 5-FU) 
and GC (gemcitabine and cisplatin) were evaluated revealed survival benefits of induction chemotherapy for nasopharyngeal carcinoma [72, 73]. Gemcitabine-based chemotherapy also showed efficacy against recurrent/ metastatic nasopharyngeal carcinoma [74].

As is the situation for molecular targeted drugs, EGFR-targeted therapy has been anticipated to be effective for nasopharyngeal cancer, and drugs that are specific to nasopharyngeal cancer (e.g., nimotuzumab) are being investigated [75]. Immune checkpoint inhibitors are also speculated to be effective for the treatment of nasopharyngeal cancer, and some small prospective trials have shown promising responses [76-78].

\section{Salivary gland carcinoma}

Salivary gland carcinoma is rare but has heterogenous histological groups [79]. The variety of the histology makes it difficult to obtain evidence regarding the treatment of salivary gland carcinomas in large-scale randomized clinical trials. Molecular targeted drugs approved for the treatment of SCCHN, i.e., EGFR inhibitors and immune checkpoint inhibitors, were also tested for salivary gland carcinoma, but their efficacy was limited to modest responses [80, 81].

In some salivary duct carcinomas, like breast cancers, the expressions of androgen receptor (AR) or human epidermal growth factor 2 (HER2) were observed to be positive, and AR-targeted hormonal therapy and a HER2-targeted antibody showed high response rates [82, 83]. HRAS-targeted therapy for HRAS-mutant cases was recently investigated [84]. Future systemic therapies for salivary gland carcinoma might be designed to be specific to each of this cancer's histological subtypes.

\section{Thyroid carcinoma}

Thyroid carcinoma has both clinically and pathologically distinct features, and thus the management strategies for this cancer have been distinguished from those for SCCHN, especially for non-surgical treatments. The incidence of thyroid cancer has recently risen, due mainly to the unintended detection of non-clinically relevant nodules by improved imaging technology [85].

The most common histology of thyroid cancers is a differentiated cancer (DTC; differentiated thyroid cancer) including papillary carcinoma and follicular carcinoma, which have indolent prognoses even in the metastatic setting. The need for and the timing of invasive treatment for the management of DTC patients have therefore been discussed in clinical practice [86, 87]. Since DTCs are resistant to the traditional cytotoxic drugs, radioiodine therapy had long been the only systemic therapy for DTC [88]. In the 2010s, several TKIs provided a clinical response and the prolongation of survival, and they were approved in the U.S., the Europe and Japan for practical use $[89,90]$. A problem is that the decision regarding when to start treatment with a TKI is not clear, because the disease progression of DTCs can be quite slow. Clinical trials have included DTC patients who were resistant to radioiodine and showed disease progression within the past 12-14 months, and the appropriate follow-up is necessary for DTC patients before introducing a TKI treatment. It was revealed that some DTC patients have BRAF mutation, and BRAF-targeted drugs have been investigated [91].

Medullary thyroid cancer (MTC) is known to be related to multiple neuroendocrine neoplasia type 2 (MEN2), but $75 \%$ of the onsets of MTC are sporadic, and MTC causes the secretion of several hormones such as calcitonin, resulting in diarrhea and/or other symptoms [92]. RET mutation has a close relationship with MTC (both hereditary and sporadic), and thus TKIs targeting RET have been investigated. Vandetanib was the first TKI that showed a survival benefit in a phase 3 trial (the ZETA trial) and was approved in the U.S., the Europe and Japan for the treatment of MTC [93]. Cabozantinib, targeting multiple tyrosine kinases RET, also improved the survival of patients with MTC [94], especially those with RET M918T mutation [95]. Treatment with the new RET inhibitor selpercatinib (LOXO-292) was reported to provide a high response rate to MTC [96].

In contrast to DTC, anaplastic thyroid cancer (ATC) is an extremely aggressive cancer, and it is known as one of the poorest-prognosis diseases. Conventionally, various cytotoxic chemotherapies including cisplatin, docetaxel or doxorubicin were tried, but they had limited clinical benefits [97]. TKIs approved to treat DTCs (e.g., sorafenib and lenvatinib) have some clinical data of efficacy against ATC, and the ATC patients achieved modest responses with these agents $[98,99]$. As with DTC, there are ATC patients with BRAF mutation, and targeting the BRAF signaling pathway might help improve the survival of ATC patients [100]. Immune checkpoint inhibitors as a treatment for ATC are also being investigated [101].

\section{Future directions}

\section{Potential new targets in head and neck cancer}

Although targeted therapies such as EGFR inhibitors and immune checkpoint inhibitors have been approved as treatments for head and neck cancers, some patients are resistant to these therapies, and thus the searching for new molecular targets continues. Vascular epidermal growth factor (VEGF), an angiogenetic factor on the cell membrane and one of the most well-studied targets for solid tumors [102], was a candidate for the targeted therapy of SCCHN, but the phase 3 trial of the anti-VEGF antibody bevacizumab did not show a survival benefit for SCCHN patients [103]. An assessment of the 
molecular landscape of SCCHN indicates that the downstreams of molecular growth factors might be candidates for new targeted therapies against SCCHN, such as phosphoinositide-3-kinase (PIK3CA), cyclindependent kinase (CDK), or the WNT signaling pathways [104]. There are prospective clinical trials of a PIK3CA inhibitor and a CDK inhibitor as treatments for SCCHN $[105,106]$.

New immunologic treatments are also under investigation. Regarding combinations with immune checkpoint inhibitors, an indoleamine 2, 3-dioxygenase 1 (IDO1)targeted therapy was a promising candidate [107], but the negative results of the phase 3 trial in malignant melanoma lessened the motivation for testing this target [108]. Aside from systemic drugs, viral therapy and cell infusion therapy as immune anticancer therapy for head and neck cancer were also investigated $[109,110]$.

\section{Local therapy with a molecular targeted strategy}

The local control of head and neck cancer directly affects both the survival and the quality of life of the patients, and thus new targeted therapies focusing on the control of the primary site or local recurrence have been examined as head and neck cancer treatments. Boron neutron capture therapy (BNCT), which is radiotherapy by neutron irradiation, targets boron compounds infused and selectively taken into tumor cells [111]. BNCT has been used in clinical practice in Finland [112], and it was approved in Japan in 2020 for the treatment of locally advanced/recurrent head and neck cancer. The published clinical data is limited to small cohorts, but they showed high response rates; one Japanese clinical trial showed $90 \%$ overall response rates to 20 head and neck cancers, including 10 locally recurrent SCC, 7 locally recurrent non-SCC and 3 locally advanced nonSCC patients [113]. The availability and feasibility of reirradiation to locally recurrent lesions which had been already treated with definitive radiation are characteristic in BNCT.

Near-infrared photoimmunotherapy (NIR-PIT) is another new local treatment strategy approved in Japan in 2020, which was developed with the progress of the photothermal and photodynamic therapies for cancers [114]. NIR-PIT consists of infusing a photo-activating chemical and the exposure of the NIR light. The photoactivating chemical includes an antibody that combines tumor cells (EGFR antibody in head and neck cancers) and a photo-absorbing dye, and the absorption of the NIR light induces a ligand-release reaction and even an antitumor immune reaction $[115,116]$. In phase 2a trial, NIR-PIT showed $50 \%$ of overall response rates to locally recurrent $\mathrm{SCCHN}$ patients who could not be satisfactory treated with other local therapies $(n=30)$ [117].
The clinical evidence of these new targeted local therapies is limited to small prospective trials, but in the future some of these therapies might replace conventional radiation therapy or even surgical treatment. For the cure of head and neck cancers and the preservation of patients' quality of life, both systemic and locally targeted treatments for head and neck cancers should be developed.

\section{Abbreviations}

ATC: Anaplastic thyroid cancer; BRT: Bioradiotherapy; BNCT: Boron neutron capture therapy; CDK: Cyclin-dependent kinase; CPS: Combined positive score; CRT: Concurrent chemoradiotherapy; CTLA-4: Cytotoxic T lymphocyte antigen-4; DTC: Differentiated thyroid cancer; EBV: Epstein-Barr virus;

EGFR: Epidermal growth factor receptor; 5-FU: 5-fluorouracil; GC: Gemcitabine and cisplatin; HER2: Human epidermal growth factor-2; HPV: human papilloma virus; IDO1: Indoleamine 2, 3-dioxygenase 1;

IHC: Immunohistochemistry; MEN2: Multiple neuroendocrine neoplasia type 2; MTC: Medullary thyroid cancer; NIR-PIT: Near-infrared

photoimmunotherapy; OS: Overall survival; PD-1: Programmed death-1; PDL1: Programmed death ligand-1; PFS: Progression-free survival;

PIK3CA: Phosphoinositide-3-kinase; PS: Performance status; QOL: Quality of life; SCC: Squamous cell carcinoma; SCCHN: Squamous cell carcinoma of the head and neck; TKI: Tyrosine kinase inhibitor; TMB: Tumor mutation burden; TPF: Taxane, platinum and 5-FU; VEGF: Vascular epidermal growth factor

\section{Code availability}

Not applicable.

Author's contributions

K.N. wrote and approved the manuscript.

Funding

Not applicable.

Availability of data and materials

Not applicable.

\section{Declarations}

Ethics approval and consent to participate

Not applicable.

Consent for publication

Not applicable.

\section{Competing interests}

None to declare.

Received: 27 October 2020 Accepted: 1 March 2021

Published online: 30 May 2021

\section{References}

1. Chow LQM. Head and neck cancer. N Engl J Med. 2020;382(1):60-72. https://doi.org/10.1056/NEJMra1715715.

2. Taberna M, Mena M, Pavón MA, Alemany L, Gillison ML, Mesía R. Human papillomavirus-related oropharyngeal cancer. Ann Oncol. 2017;28(10):238698. https://doi.org/10.1093/annonc/mdx304.

3. Chen YP, Chan ATC, Le QT, Blanchard P, Sun Y, Ma J. Nasopharyngeal carcinoma. Lancet. 2019;394(10192):64-80. https://doi.org/10.1016/S01406736(19)30956-0.

4. Sacco AG, Cohen EE. Current treatment options for recurrent or metastatic head and neck squamous cell carcinoma. J Clin Oncol. 2015;33(29):3305-13. https://doi.org/10.1200/JCO.2015.62.0963.

5. Brana I, Siu LL. Locally advanced head and neck squamous cell cancer: treatment choice based on risk factors and optimizing drug prescription. Ann Oncol. 2012;23(Suppl 10):x178-85. https://doi.org/10.1093/annonc/ mds322. 
6. Lefebvre JL, Chevalier D, Luboinski B, Kirkpatrick A, Collette L, Sahmoud T. Larynx preservation in pyriform sinus cancer: preliminary results of a European Organization for Research and Treatment of Cancer phase III trial. EORTC head and neck Cancer cooperative group. J Natl Cancer Inst. 1996; 88(13):890-9. https://doi.org/10.1093/jnci/88.13.890.

7. Pignon JP, Bourhis J, Domenge C, Designé L. Chemotherapy added to locoregional treatment for head and neck squamous-cell carcinoma. Three meta-analyses of updated individual data. MACH-NC collaborative group. Meta-analysis of chemotherapy on head and neck Cancer. Lancet. 2000; 355(9208):949-55. https://doi.org/10.1016/50140-6736(00)90011-4.

8. Cooper JS, Pajak TF, Forastiere AA, Jacobs J, Campbell BH, Saxman SB, et al. Radiation therapy oncology group 9501/intergroup. Postoperative concurrent radiotherapy and chemotherapy for high-risk squamous-cell carcinoma of the head and neck. N Engl J Med. 2004;350(19):1937-44. https://doi.org/10.1056/NEJMoa032646.

9. Bernier J, Domenge C, Ozsahin M, Matuszewska K, Lefèbvre JL, Greiner RH, et al. European Organization for Research and Treatment of Cancer trial 22931. Postoperative irradiation with or without concomitant chemotherapy for locally advanced head and neck cancer. N Engl J Med. 2004;350(19): 1945-52. https://doi.org/10.1056/NEJMoa032641.

10. Kiyota N, Tahara M, Fujii H, Yamazaki T, Mitani H, Iwae S, et al. Phase I//II trial of post-operative chemoradiotherapy comparing 3-weekly cisplatin with weekly cisplatin in high-risk patients with squamous cell carcinoma of head and neck (JCOG1008). J Clin Oncol. 2020;38: 6502. no. 15_suppl. https://doi.org/10.1200/JCO.2020.38.15_suppl.6502.

11. Vermorken JB, Remenar E, van Herpen C, Gorlia T, Mesia R, Degardin M, et al. EORTC 24971/TAX 323 study group. Cisplatin, fluorouracil, and docetaxel in unresectable head and neck cancer. N Engl J Med. 2007; 357(17):1695-704. https://doi.org/10.1056/NEJMoa071028.

12. Posner MR, Hershock DM, Blajman CR, Mickiewicz E, Winquist E, Gorbounova V, et al. TAX 324 study group. Cisplatin and fluorouracil alone or with docetaxel in head and neck cancer. N Engl J Med. 2007;357(17): 1705-15. https://doi.org/10.1056/NEJMoa070956.

13. Budach W, Bölke E, Kammers K, Gerber PA, Orth K, Gripp S, et al. Induction chemotherapy followed by concurrent radio-chemotherapy versus concurrent radio-chemotherapy alone as treatment of locally advanced squamous cell carcinoma of the head and neck (HNSCC): a meta-analysis of randomized trials. Radiother Oncol. 2016;1 18(2):238-43. https://doi.org/10.1 016/j.radonc.2015.10.014

14. Haddad Rl, Posner M, Hitt R, Cohen EEW, Schulten J, Lefebvre JL, et al. Induction chemotherapy in locally advanced squamous cell carcinoma of the head and neck: role, controversy, and future directions. Ann Oncol. 2018;29(5):1130-40. https://doi.org/10.1093/annonc/mdy102.

15. Lin JT, Lai GM, Chang TH, Liu MT, Bi CP, Wang JW, et al. Chemotherapy with modified docetaxel, cisplatin, and 5-fluorouracil in patients with metastatic head and neck cancer. Adv Ther. 2012;29(1):71-7. https://doi.org/10.1007/ s12325-011-0085-2.

16. Cho H, Nishiike S, Yamamoto Y, Takenaka Y, Nakahara S, Yasui T, et al. Docetaxel, cisplatin, and fluorouracil for patients with inoperable recurrent or metastatic head and neck squamous cell carcinoma. Auris Nasus Larynx. 2015;42(5):396-400. https://doi.org/10.1016/.anl.2015.02.009.

17. Yossi S, Linot B, Peyraga G, Breheret R, Laccourreye L, Capitain O. Feasibility and safety of dose-dense modified docetaxel-cisplatin or carboplatin and 5fluorouracil regimen (mTPF) in locally advanced or metastatic head and neck cancers: a retrospective monocentric study. Int J Clin Oncol. 2015;20(6): 1086-92. https://doi.org/10.1007/s10147-015-0836-1.

18. Baselga J, Arteaga CL. Critical update and emerging trends in epidermal growth factor receptor targeting in cancer. J Clin Oncol. 2005;23(11):244559. https://doi.org/10.1200/JCO.2005.11.890.

19. Bonner JA, Harari PM, Giralt J, Azarnia N, Shin DM, Cohen RB, et al. Radiotherapy plus cetuximab for squamous-cell carcinoma of the head and neck. N Engl J Med. 2006;354(6):567-78. https://doi.org/10.1056/NEJMoa053422.

20. Vermorken JB, Mesia R, Rivera F, Remenar E, Kawecki A, Rottey S, et al. Platinum-based chemotherapy plus cetuximab in head and neck cancer. N Engl J Med. 2008;359(11):1116-27. https://doi.org/10.1056/NEJMoa 0802656 .

21. Lefebvre JL, Pointreau $Y$, Rolland F, Alfonsi M, Baudoux A, Sire C, et al. Induction chemotherapy followed by either chemoradiotherapy or bioradiotherapy for larynx preservation: The TREMPLIN randomized phase II study. J Clin Oncol. 2013;31(7):853-9. https://doi.org/10.1200/ JCO.2012.42.3988.
22. Ghi MG, Paccagnella A, Ferrari D, Foa P, Alterio D, Codecà C, et al. Induction TPF followed by concomitant treatment versus concomitant treatment alone in locally advanced head and neck cancer. A phase II-III trial. Ann Oncol. 2017;28(9):2206-12. https://doi.org/10.1093/annonc/mdx299.

23. Geoffrois $L$, Martin $L$, De Raucourt D, Sun XS, Tao Y, et al. Induction chemotherapy followed by cetuximab radiotherapy is not superior to concurrent chemoradiotherapy for head and neck carcinomas: results of the GORTEC 2007-02 phase III randomized trial. J Clin Oncol. 2018;36(31):307783. https://doi.org/10.1200/JCO.2017.76.2591.

24. Ang KK, Zhang Q, Rosenthal DI, Nguyen-Tan PF, Sherman EJ, Weber RS, et al. Randomized phase III trial of concurrent accelerated radiation plus cisplatin with or without cetuximab for stage III to IV head and neck carcinoma: RTOG 0522. J Clin Oncol. 2014;32(27):2940-50. https://doi.org/1 0.1200/JCO.2013.53.5633

25. Tao Y, Auperin A, Sire C, Martin L, Khoury C, Maingon P, et al. Improved outcome by adding concurrent chemotherapy to cetuximab and radiotherapy for locally advanced head and neck carcinomas: Results of the GORTEC 2007-01 phase III randomized trial. J Clin Oncol. 2018: JCO2017762518. https://doi.org/10.1200/JCO.2017.76.2518.

26. Bernier J, Bonner J, Vermorken JB, Bensadoun RJ, Dummer R, Giralt J, et al. Consensus guidelines for the management of radiation dermatitis and coexisting acne-like rash in patients receiving radiotherapy plus EGFR inhibitors for the treatment of squamous cell carcinoma of the head and neck. Ann Oncol. 2008;19(1):142-9. https://doi.org/10.1093/annonc/mdm400.

27. Cao Y, Liao C, Tan A, Liu L, Gao F. Meta-analysis of incidence and risk of hypomagnesemia with cetuximab for advanced cancer. Chemotherapy. 2010;56(6):459-65. https://doi.org/10.1159/000321011.

28. Nakano K, Seto A, Sasaki T, Shimbashi W, Fukushima H, Yonekawa H, et al. Incidence and risk factors of interstitial lung disease of patients with head and neck cancer treated with cetuximab. Head Neck. 2019;41(8):2574-80. https://doi.org/10.1002/hed.25727.

29. Hitt R, Irigoyen A, Cortes-Funes H, Grau JJ, García-Sáenz JA, Cruz-Hernandez JJ. Spanish head and neck Cancer cooperative group (TTC). Phase II study of the combination of cetuximab and weekly paclitaxel in the first-line treatment of patients with recurrent and/or metastatic squamous cell carcinoma of head and neck. Ann Oncol. 2012;23(4):1016-22. https://doi. org/10.1093/annonc/mdr367.

30. Péron J, Ceruse P, Lavergne E, Buiret G, Pham BN, Chabaud S, et al. Paclitaxel and cetuximab combination efficiency after the failure of a platinum-based chemotherapy in recurrent/metastatic head and neck squamous cell carcinoma. Anti-Cancer Drugs. 2012;23(9):996-1001. https:// doi.org/10.1097/CAD.0b013e32835507e5.

31. Tahara M, Kiyota N, Yokota T, Hasegawa Y, Muro K, Takahashi S, et al. Phase Il trial of combination treatment with paclitaxel, carboplatin and cetuximab (PCE) as first-line treatment in patients with recurrent and/or metastatic squamous cell carcinoma of the head and neck (CSPOR-HNO2). Ann Oncol. 2018:29(4):1004-9. https://doi.org/10.1093/annonc/mdy040.

32. Remon J, Ahn MJ, Girard N, Johnson M, Kim DW, Lopes G, et al. Advancedstage non-small cell lung cancer: advances in thoracic oncology 2018. J Thorac Oncol. 2019;14(7):1134-55. https://doi.org/10.1016/j.tho.2019.03.022.

33. Argiris A, Ghebremichael M, Gilbert J, Lee JW, Sachidanandam K, Kolesar JM, et al. Phase III randomized, placebo-controlled trial of docetaxel with or without gefitinib in recurrent or metastatic head and neck cancer: an eastern cooperative oncology Ggroup trial. J Clin Oncol. 2013;31(11):140514. https://doi.org/10.1200/JCO.2012.45.4272.

34. Martins RG, Parvathaneni U, Bauman JE, Sharma AK, Raez LE, Papagikos MA, et al. Cisplatin and radiotherapy with or without erlotinib in locally advanced squamous cell carcinoma of the head and neck: a randomized phase II trial. J Clin Oncol. 2013;31(11):1415-21. https://doi.org/10.1200/ JCO.2012.46.3299.

35. Machiels JP, Haddad RI, Fayette J, Licitra LF, Tahara M, Vermorken JB, et al. LUX-H\&N 1 investigators. Afatinib versus methotrexate as second-line treatment in patients with recurrent or metastatic squamous-cell carcinoma of the head and neck progressing on or after platinum-based therapy (LUXHead \& Neck 1): an open-label, randomised phase 3 trial. Lancet Oncol. 2015;16(5):583-94. https://doi.org/10.1016/51470-2045(15)70124-5.

36. Burtness B, Haddad R, Dinis J, Trigo J, Yokota T, de Souza VL, et al. LUXHead \& Neck 2 investigators. Afatinib vs placebo as adjuvant therapy after chemoradiotherapy in squamous cell carcinoma of the head and neck: a randomized clinical trial. JAMA Oncol. 2019;5(8):1170-80. https://doi.org/10.1 001/jamaoncol.2019.1146. 
37. Guo Y, Ahn MJ, Chan A, Wang CH, Kang JH, Kim SB, et al. Afatinib versus methotrexate as second-line treatment in Asian patients with recurrent or metastatic squamous cell carcinoma of the head and neck progressing on or after platinum-based therapy (LUX-Head \& Neck 3): an open-label, randomised phase III trial. Ann Oncol. 2019;30(11):1831-9. https://doi.org/1 0.1093/annonc/mdz388.

38. Siu LL, Waldron JN, Chen BE, Winquist E, Wright JR, Nabid A, et al. Effect of standard radiotherapy with cisplatin vs accelerated radiotherapy with panitumumab in locoregionally advanced squamous cell head and neck carcinoma: a randomized clinical trial. JAMA Oncol. 2017;3(2):220-6. https:// doi.org/10.1001/jamaoncol.2016.4510.

39. Vermorken JB, Stöhlmacher-Williams J, Davidenko I, Licitra L, Winquist E, Villanueva C, et al. Cisplatin and fluorouracil with or without panitumumab in patients with recurrent or metastatic squamous-cell carcinoma of the head and neck (SPECTRUM): an open-label phase 3 randomised trial. Lancet Oncol. 2013;14(8):697-710. https://doi.org/10.1016/S1470-2045(13)70181-5.

40. Linardou H, Dahabreh IJ, Kanaloupiti D, Siannis F, Bafaloukos D, Kosmidis P, et al. Assessment of somatic k-RAS mutations as a mechanism associated with resistance to EGFR-targeted agents: a systematic review and metaanalysis of studies in advanced non-small-cell lung cancer and metastatic colorectal cancer. Lancet Oncol. 2008;9(10):962-72. https://doi.org/10.1016/ S1470-2045(08)70206-7.

41. Sepulveda AR, Hamilton SR, Allegra CJ, Grody W, Cushman-Vokoun AM, Funkhouser WK, et al. Molecular biomarkers for the evaluation of colorectal cancer: guideline from the American Society for Clinical Pathology, College of American Pathologists, Association for Molecular Pathology, and the American Society of Clinical Oncology. J Clin Oncol. 2017;35(13):1453-86. https://doi.org/10.1200/JCO.2016.71.9807.

42. Licitra L, Mesia R, Rivera F, Remenár É, Hitt R, Erfán J, et al. Evaluation of EGFR gene copy number as a predictive biomarker for the efficacy of cetuximab in combination with chemotherapy in the first-line treatment of recurrent and/or metastatic squamous cell carcinoma of the head and neck: EXTREME study. Ann Oncol. 2011;22(5):1078-87. https://doi.org/10.1093/a nnonc/mdq588.

43. Fujii S, Uryu H, Akashi K, Suzuki K, Yamazaki M, Tahara M, et al. Clinical significance of KRAS gene mutation and epidermal growth factor receptor expression in Japanese patients with squamous cell carcinoma of the larynx, oropharynx and hypopharynx. Int J Clin Oncol. 2013;18(3):454-63. https://doi.org/10.1007/s10147-012-0402-z.

44. Weidhaas JB, Harris J, Schaue D, Chen AM, Chin R, Axelrod R, et al. The KRAS-variant and cetuximab response in head and neck squamous cell cancer: a secondary analysis of a randomized clinical trial. JAMA Oncol. 2017;3(4):483-91. https://doi.org/10.1001/jamaoncol.2016.5478.

45. Ang KK, Harris J, Wheeler R, Weber R, Rosenthal DI, Nguyen-Tân PF, et al. Human papillomavirus and survival of patients with oropharyngeal cancer. N Engl J Med. 2010;363(1):24-35. https://doi.org/10.1056/NEJMoa0912217.

46. Rosenthal DI, Harari PM, Giralt J, Bell D, Raben D, Liu J, et al. Association of Human Papillomavirus and p16 status with outcomes in the IMCL-9815 phase III registration trial for patients with locoregionally advanced oropharyngeal squamous cell carcinoma of the head and neck treated with radiotherapy with or without cetuximab. J Clin Oncol. 2016;34(12):1300-8. https://doi.org/10.1200/JCO.2015.62.5970.

47. Vermorken JB, Psyrri A, Mesía R, Peyrade F, Beier F, de Blas B, et al. Impact of tumor HPV status on outcome in patients with recurrent and/or metastatic squamous cell carcinoma of the head and neck receiving chemotherapy with or without cetuximab: retrospective analysis of the phase III EXTREME trial. Ann Oncol. 2014;25(4):801-7. https://doi.org/10.1093/annonc/mdt574.

48. Gillison ML, Trotti AM, Harris J, Eisbruch A, Harari PM, Adelstein DJ, et al. Radiotherapy plus cetuximab or cisplatin in human papillomavirus-positive oropharyngeal cancer (NRG Oncology RTOG 1016): A randomised, multicentre, non-inferiority trial. Lancet. 2019;393(10166):40-50. https://doi. org/10.1016/S0140-6736(18)32779-X.

49. Ribas A, Wolchok JD. Cancer immunotherapy using checkpoint blockade. Science. 2018;359(6382):1350-5. https://doi.org/10.1126/science.aar4060.

50. Lawrence MS, Stojanov P, Polak P, Kryukov GV, Cibulskis K, Sivachenko A, et al. Mutational heterogeneity in cancer and the search for new cancer-associated genes. Nature. 2013;499(7457):214-8. https://doi.org/10.1038/nature12213.

51. Ferris RL, Blumenschein G Jr, Fayette J, Guigay J, Colevas AD, Licitra L, et al. Nivolumab for recurrent squamous-cell carcinoma of the head and neck. N Engl J Med. 2016;375(19):1856-67. https://doi.org/10.1056/ NEJMoa1602252.
52. Cohen EEW, Soulières D, Le Tourneau C, Dinis J, Licitra L, Ahn MJ, et al. Pembrolizumab versus methotrexate, docetaxel, or cetuximab for recurrent or metastatic head-and-neck squamous cell carcinoma (KEYNOTE-040): A randomised, open-label, phase 3 study. Lancet. 2019;393(10167):156-67. https://doi.org/10.1016/S0140-6736(18)31999-8.

53. Burtness $B$, Harrington $K J$, Greil R, Soulières $D$, Tahara $M$, de Castro $G$ Jr, et al. Pembrolizumab alone or with chemotherapy versus cetuximab with chemotherapy for recurrent or metastatic squamous cell carcinoma of the head and neck (KEYNOTE-048): A randomised, openlabel, phase 3 study. Lancet. 2019;394(10212):1915-28. https://doi.org/1 0.1016/S0140-6736(19)32591-7.

54. Antonia SJ, Villegas A, Daniel D, Vicente D, Murakami S, Hui R, et al. Durvalumab after chemoradiotherapy in stage III non-small-cell lung cancer. N Engl J Med. 2017;377(20):1919-29. https://doi.org/10.1056/ NEJMoa1709937.

55. Paz-Ares L, Dvorkin M, Chen Y, Reinmuth N, Hotta K, Trukhin D, et al. Durvalumab plus platinum-etoposide versus platinum-etoposide in first-line treatment of extensive-stage small-cell lung cancer (CASPIAN): a randomised, controlled, open-label, phase 3 trial. Lancet. 2019;394(10212): 1929-39. https://doi.org/10.1016/S0140-6736(19)32222-6.

56. Ferris RL, Haddad R, Even C, Tahara M, Dvorkin M, Ciuleanu TE, et al. Durvalumab with or without tremelimumab in patients with recurrent or metastatic head and neck squamous cell carcinoma: EAGLE, a randomized, open-label phase III study. Ann Oncol. 2020;31(7):942-50. https://doi.org/1 0.1016/j.annonc.2020.04.001.

57. Versluis JM, Long GV, Blank CU. Learning from clinical trials of neoadjuvant checkpoint blockade. Nat Med. 2020;26(4):475-84. https://doi.org/10.1038/ s41591-020-0829-0.

58. Schoenfeld JD, Hanna GJ, Jo VY, Rawal B, Chen YH, Catalano PS, et al. Neoadjuvant nivolumab or nivolumab plus ipilimumab in untreated oral cavity squamous cell carcinoma: a phase 2 open-label randomized clinical trial. JAMA Oncol. 2020;6(10):1-9. https://doi.org/10.1001/jama oncol.2020.2955.

59. Coleman CN, Eke I, Makinde AY, Chopra S, Demaria S, Formenti SC, et al. Radiation-unduced adaptive response: new potential for Cancer treatment. Clin Cancer Res. 2020;26(22):5781-90. https://doi.org/10.1158/1078-0432. CCR-20-0572

60. Weiss J, Sheth S, Deal AM, Grilley Olson JE, Patel S, Hackman TG, et al. Concurrent definitive immunoradiotherapy for patients with stage III-IV head and neck cancer and cisplatin contraindication. Clin Cancer Res. 2020; 26(16):4260-7. https://doi.org/10.1158/1078-0432.CCR-20-0230.

61. Powell SF, Gold KA, Gitau MM, Sumey CJ, Lohr MM, MCGraw SC, et al. Safety and efficacy of pembrolizumab with chemoradiotherapy in locally advanced head and neck squamous cell carcinoma: a phase IB study. J Clin Oncol. 2020;38(21):2427-37. https://doi.org/10.1200/JCO.19.03156.

62. Elbers JBW, Al-Mamgani A, Tesseslaar MET, van den Brekel MWM, Lange $\mathrm{CAH}$, van der Wal JE, et al. Immuno-radiotherapy with cetuximab and avelumab for advanced stage head and neck squamous cell carcinoma: results from a phase-I trial. Radiother Oncol. 2020;142:79-84. https://doi. org/10.1016/j.radonc.2019.08.007.

63. Cohen EE, Ferris RL, Psyrri A, Haddad R, Tahara M, Bourhis J, et al. Primary results of the phase III JAVELIN head \& neck 100 trial: Avelumab plus chemoradiotherapy (CRT) followed by avelumab maintenance vs CRT in patients with locally advanced squamous cell carcinoma of the head and neck (LA SCCHN). Ann Oncol. 2020;31:S658. https://doi.org/10.1016/a nnonc/annonc277.

64. Havel JJ, Chowell D, Chan TA. The evolving landscape of biomarkers for checkpoint inhibitor immunotherapy. Nat Rev Cancer. 2019;19(3):133-50. https://doi.org/10.1038/s41568-019-0116-X.

65. Reck M, Rodríguez-Abreu D, Robinson AG, Hui R, Csőszi T, Fülöp A, et al. Pembrolizumab versus chemotherapy for PD-L1-positive non-small-cell lung cancer. N Engl J Med. 2016:375(19):1823-33. https://doi.org/10.1056/ NEJMoa1606774.

66. Schmid P, Adams S, Rugo HS, Schneeweiss A, Barrios $\mathrm{CH}$, Iwata $\mathrm{H}$, et al. Atezolizumab and nab-paclitaxel in advanced triple-negative breast cancer. N Engl J Med. 2018;379(22):2108-21. https://doi.org/10.1056/ NEJMoa1809615.

67. Bauml J, Seiwert TY, Pfister DG, Worden F, Liu SV, Gilbert J, et al. Pembrolizumab for platinum- and cetuximab-refractory head and neck cancer: results from a single-arm, phase II study. J Clin Oncol. 2017;35(14): 1542-9. https://doi.org/10.1200/JCO.2016.70.1524. 
68. Seiwert TY, Burtness B, Mehra R, Weiss J, Berger R, Eder JP, et al. Safety and clinical activity of pembrolizumab for treatment of recurrent or metastatic squamous cell carcinoma of the head and neck (KEYNOTE-012): an openlabel, multicentre, phase 1b trial. Lancet Oncol. 2016;17(7):956-65. https:// doi.org/10.1016/S1470-2045(16)30066-3.

69. Saâda-Bouzid E, Defaucheux C, Karabajakian A, Coloma VP, Servois V, Paoletti $X$, et al. Hyperprogression during anti-PD-1/PD-L1 therapy in patients with recurrent and/or metastatic head and neck squamous cell carcinoma. Ann Oncol. 2017;28(7):1605-11. https://doi.org/10.1093/annonc/ $\mathrm{mdx} 178$.

70. Al-Sarraf M, LeBlanc M, Giri PG, Fu KK, Cooper J, Vuong T, et al. Chemoradiotherapy versus radiotherapy in patients with advanced nasopharyngeal cancer: phase III randomized intergroup study 0099. J Clin Oncol. 1998;16(4):1310-7. https://doi.org/10.1200/JCO.1998.16.4.1310.

71. Chen L, Hu CS, Chen XZ, Hu GQ, Cheng ZB, Sun Y, et al. Concurrent chemoradiotherapy plus adjuvant chemotherapy versus concurrent chemoradiotherapy alone in patients with locoregionally advanced nasopharyngeal carcinoma: a phase 3 multicentre randomised controlled trial. Lancet Oncol. 2012;13(2):163-71. https://doi.org/10.1016/S1470-2045(11)70320-5.

72. Sun Y, Li WF, Chen NY, Zhang N, Hu GQ, Xie FY, et al. Induction chemotherapy plus concurrent chemoradiotherapy versus concurrent chemoradiotherapy alone in locoregionally advanced nasopharyngeal carcinoma: a phase 3, multicentre, randomised controlled trial. Lancet Oncol. 2016;17(11):1509-20. https://doi.org/10.1016/S1470-2045(16)30410-7.

73. Zhang Y, Chen L, Hu GQ, Zhang N, Zhu XD, Yang KY, et al. Gemcitabine and cisplatin induction chemotherapy in nasopharyngeal carcinoma. N Engl J Med. 2019;381(12):1124-35. https://doi.org/10.1056/NEJMoa1905287.

74. Zhang L, Huang Y, Hong S, Yang Y, Yu G, Jia J, et al. Gemcitabine plus cisplatin versus fluorouracil plus cisplatin in recurrent or metastatic nasopharyngeal carcinoma: A multicentre, randomised, open-label, phase 3 trial. Lancet. 2016;388(10054):1883-92. https://doi.org/10.1016/S0140-6736(1 6)31388-5. Erratum in: Lancet. 2016;388(10054):1882. PMID: 27567279.

75. Chen X, Liang R, Zhu X. Anti-EGFR therapies in nasopharyngeal carcinoma. Biomed Pharmacother. 2020;131:110649. https://doi.org/10.1016/j.biopha.202 0.110649 .

76. Hsu C, Lee SH, Ejadi S, Even C, Cohen RB, Le Tourneau C, et al. Safety and antitumor activity of pembrolizumab in patients with programmed deathligand 1-positive nasopharyngeal carcinoma: results of the KEYNOTE-028 study. J Clin Oncol. 2017;35(36):4050-6. https://doi.org/10.1200/JCO.2017. 73.3675 .

77. Ma BBY, Lim WT, Goh BC, Hui EP, Lo KW, Pettinger A, et al. Antitumor activity of nivolumab in recurrent and metastatic nasopharyngeal carcinoma: An international, multicenter study of the Mayo Clinic Phase 2 Consortium (NCl-9742). J Clin Oncol. 2018;36(14):1412-8. https://doi.org/1 $0.1200 / J C O .2017 .77 .0388$

78. Fang W, Yang Y, Ma Y, Hong S, Lin L, He X, et al. Camrelizumab (SHR-1210) alone or in combination with gemcitabine plus cisplatin for nasopharyngeal carcinoma: results from two single-arm, phase 1 trials. Lancet Oncol. 2018; 19(10):1338-50. https://doi.org/10.1016/S1470-2045(18)30495-9.

79. Yin LX, Ha PK. Genetic alterations in salivary gland cancers. Cancer. 2016; 122(12):1822-31. https://doi.org/10.1002/cncr.29890.

80. Kawahara K, Hiraki A, Yoshida R, Arita H, Matsuoka Y, Yamashita T, et al. Salivary duct carcinoma treated with cetuximab-based targeted therapy: A case report. Mol Clin Oncol. 2017;6(6):886-92. https://doi.org/10.3892/mco.2 017.1226.

81. Cohen RB, Delord JP, Doi T, Piha-Paul SA, Liu SV, Gilbert J, et al. Pembrolizumab for the treatment of advanced salivary gland carcinoma: findings of the phase 1b KEYNOTE-028 study. Am J Clin Oncol. 2018;41(11): 1083-8. https://doi.org/10.1097/COC.0000000000000429.

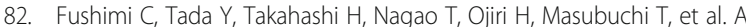
prospective phase II study of combined androgen blockade in patients with androgen receptor-positive metastatic or locally advanced unresectable salivary gland carcinoma. Ann Oncol. 2018;29(4):979-84. https://doi.org/10.1 093/annonc/mdx771.

83. Takahashi H, Tada Y, Saotome T, Akazawa K, Ojiri H, Fushimi C, et al. Phase II trial of trastuzumab and docetaxel in patients with human epidermal growth factor receptor 2-positive salivary duct carcinoma. J Clin Oncol. 2019;37(2):125-34. https://doi.org/10.1200/JCO.18.00545.

84. Hanna GJ, Guenette JP, Chau NG, Sayehli CM, Wilhelm C, Metcalf R, et al. Tipifarnib in recurrent, metastatic HRAS-mutant salivary gland cancer. Cancer. 2020;126(17):3972-81. https://doi.org/10.1002/cncr.33036.
85. Cabanillas ME, McFadden DG, Durante C. Thyroid cancer. Lancet. 2016; 388(10061):2783-95. https://doi.org/10.1016/S0140-6736(16)30172-6.

86. Haugen BR, Alexander EK, Bible KC, Doherty GM, Mandel SJ, Nikiforov YE, et al. 2015 American Thyroid Association management guidelines for adult patients with thyroid nodules and differentiated thyroid cancer: the American Thyroid Association guidelines task force on thyroid nodules and differentiated thyroid Cancer. Thyroid. 2016;26(1):1-133. https://doi.org/10.1 089/thy. 2015.0020

87. Raue F, Frank-Raue K. Thyroid cancer: risk-stratified management and individualized therapy. Clin Cancer Res. 2016;22(20):5012-21. https://doi. org/10.1158/1078-0432.CCR-16-0484.

88. Giovanella L, Scappaticcio L. Radioiodine therapy of advanced differentiated thyroid cancer: Clinical considerations and multidisciplinary approach. QJ Nucl Med Mol Imaging. 2019;63(3):229-34. https://doi.org/10.23736/S1824-4 785.19.03190-X

89. Brose MS, Nutting CM, Jarzab B, Elisei R, Siena S, Bastholt L, et al. Sorafenib in radioactive iodine-refractory, locally advanced or metastatic differentiated thyroid cancer: a randomised, double-blind, phase 3 trial. Lancet. 2014; 384(9940):319-28. https://doi.org/10.1016/S0140-6736(14)60421-9.

90. Schlumberger M, Tahara M, Wirth LJ, Robinson B, Brose MS, Elisei R, et al. Lenvatinib versus placebo in radioiodine-refractory thyroid cancer. N Engl J Med. 2015;372(7):621-30. https://doi.org/10.1056/NEJMoa1406470.

91. Brose MS, Cabanillas ME, Cohen EE, Wirth LJ, Riehl T, Yue H, et al. Vemurafenib in patients with BRAF(V600E)-positive metastatic or unresectable papillary thyroid cancer refractory to radioactive iodine: a nonrandomised, multicentre, open-label, phase 2 trial. Lancet Oncol. 2016;17(9): 1272-82. https://doi.org/10.1016/S1470-2045(16)30166-8.

92. Hadoux J, Pacini F, Tuttle RM, Schlumberger M. Management of advanced medullary thyroid cancer. Lancet Diabetes Endocrinol. 2016;4(1):64-71. https://doi.org/10.1016/S2213-8587(15)00337-X

93. Wells SA Jr, Robinson BG, Gagel RF, Dralle H, Fagin JA, Santoro M, et al. Vandetanib in patients with locally advanced or metastatic medullary thyroid cancer: A randomized, double-blind phase III trial. J Clin Oncol. 2012; 30(2):134-41. https://doi.org/10.1200/JCO.2011.35.5040.

94. Elisei R, Schlumberger MJ, Müller SP, Schöffski P, Brose MS, Shah MH, et al. Cabozantinib in progressive medullary thyroid cancer. J Clin Oncol. 2013; 31(29):3639-46. https://doi.org/10.1200/JCO.2012.48.4659.

95. Schlumberger $M$, Elisei $R$, Müller $S$, Schöffski $P$, Brose $M$, Shah $M$, et al. Overall survival analysis of EXAM, a phase III trial of cabozantinib in patients with radiographically progressive medullary thyroid carcinoma. Ann Oncol. 2017;28(11):2813-9. https://doi.org/10.1093/annonc/mdx479.

96. Wirth LJ, Sherman E, Robinson B, Solomon B, Kang H, Lorch J, et al. Efficacy of selpercatinib in RET-altered thyroid cancers. N Engl J Med. 2020;383(9): 825-35. https://doi.org/10.1056/NEJMoa2005651.

97. Haddad RI, Lydiatt WM, Ball DW, Busaidy NL, Byrd D, Callender G, et al. Anaplastic thyroid carcinoma, version 2.2015. J Natl Compr Cancer Netw. 2015;13(9):1140-50. https://doi.org/10.6004/jncen.2015.0139.

98. Ito Y, Onoda N, Ito Kl, Sugitani I, Takahashi S, Yamaguchi I, et al. Sorafenib in Japanese patients with locally advanced or metastatic medullary thyroid carcinoma and anaplastic thyroid carcinoma. Thyroid. 2017;27(9):1142-8. https://doi.org/10.1089/thy.2016.0621.

99. Tahara M, Kiyota N, Yamazaki T, Chayahara N, Nakano K, Inagaki L, et al. Lenvatinib for anaplastic thyroid cancer. Front Oncol. 2017;7:25. https://doi. org/10.3389/fonc.2017.00025

100. Maniakas A, Dadu R, Busaidy NL, Wang JR, Ferrarotto R, Lu C, et al. Evaluation of overall survival in patients with anaplastic thyroid carcinoma, 2000-2019. JAMA Oncol. 2020;6(9):1-8. https://doi.org/10.1001/jamaoncol.2020.3362.

101. Capdevila J, Wirth L, Ernst T, Ponce Aix S, Lin CC, Ramlau R, et al. PD-1 blockade in anaplastic thyroid carcinoma. J Clin Oncol. 2020;38(23):2620-7. https://doi.org/10.1200/JCO.19.02727.

102. Jászai J, Schmidt MHH. Trends and challenges in tumor anti-angiogenic therapies. Cells. 2019;8(9):1102. https://doi.org/10.3390/cells8091102.

103. Argiris A, Li S, Savvides P, Ohr JP, Gilbert J, Levine MA, et al. Phase III randomized trial of chemotherapy with or without bevacizumab in patients with recurrent or metastatic head and neck cancer. J Clin Oncol. 2019; 37(34):3266-74. https://doi.org/10.1200/JCO.19.00555.

104. Leemans CR, Snijders PJF, Brakenhoff RH. The molecular landscape of head and neck cancer. Nat Rev Cancer. 2018;18(5):269-82. https://doi.org/10.1038/ nrc.2018.11

105. Soulières D, Faivre S, Mesía R, Remenár É, Li SH, Karpenko A, et al. Buparlisib and paclitaxel in patients with platinum-pretreated recurrent or metastatic 
squamous cell carcinoma of the head and neck (BERIL-1): a randomised, double-blind, placebo-controlled phase 2 trial. Lancet Oncol. 2017;18(3): 323-35. https://doi.org/10.1016/S1470-2045(17)30064-5.

106. Adkins D, Ley J, Neupane P, Worden F, Sacco AG, Palka K, et al. Palbociclib and cetuximab in platinum-resistant and in cetuximab-resistant human papillomavirus-unrelated head and neck cancer: a multicentre, multigroup, phase 2 trial. Lancet Oncol. 2019;20(9):1295-305. https://doi.org/10.1016/S14 70-2045(19)30405-X.

107. Mitchell TC, Hamid O, Smith DC, Bauer TM, Wasser JS, Olszanski AJ, et al. Epacadostat plus pembrolizumab in patients with advanced solid tumors: phase I results from a multicenter, open-label phase I//I trial (ECHO-202/ KEYNOTE-037). J Clin Oncol. 2018;36(32):3223-30. https://doi.org/10.1200/ JCO.2018.78.9602

108. Long GV, Dummer R, Hamid O, Gajewski TF, Caglevic C, Dalle S, et al. Epacadostat plus pembrolizumab versus placebo plus pembrolizumab in patients with unresectable or metastatic melanoma (ECHO-301/KEYNOTE252): a phase 3, randomised, double-blind study. Lancet Oncol. 2019;20(8): 1083-97. https://doi.org/10.1016/S1470-2045(19)30274-8.

109. Harrington KJ, Kong A, Mach N, Chesney JA, Fernandez BC, Rischin D, et al. Talimogene Laherparepvec and pembrolizumab in recurrent or metastatic squamous cell carcinoma of the head and neck (MASTERKEY-232): a multicenter, phase 1b study. Clin Cancer Res. 2020;26(19):5153-61. https:// doi.org/10.1158/1078-0432.CCR-20-1170.

110. Doran SL, Stevanović S, Adhikary S, Gartner JJ, Jia L, Kwong MLM, et al. Tcell receptor gene therapy for human papillomavirus-associated epithelial cancers: a first-in-human, phase 1//l study. J Clin Oncol. 2019;37(30):2759-68. https://doi.org/10.1200/JCO.18.02424.

111. Suzuki M. Boron neutron capture therapy (BNCT): a unique role in radiotherapy with a view to entering the accelerator-based BNCT era. Int J Clin Oncol. 2020;25(1):43-50. https://doi.org/10.1007/s10147-019-01480-4.

112. Savolainen S, Kortesniemi M, Timonen M, Reijonen V, Kuusela L, Uusi-Simola $J$, et al. Boron neutron capture therapy (BNCT) in Finland: technological and physical prospects after 20 years of experiences. Phys Med. 2013;29(3):23348. https://doi.org/10.1016/j.jmp.2012.04.008.

113. Aihara T, Morita N, Kamitani N, Kumada H, Ono K, Hiratsuka J, et al. BNCT for advanced or recurrent head and neck cancer. Appl Radiat Isot. 2014;88:12-5. https://doi.org/10.1016/k.apradiso.2014.04.007.

114. Li X, Lovell JF, Yoon J, Chen X. Clinical development and potential of photothermal and photodynamic therapies for cancer. Nature Rev Clin Oncol. 2020;17(11):657-74. https://doi.org/10.1038/s41571-020-0410-2.

115. Kobayashi H, Choyke PL. Near-infrared photoimmunotherapy of cancer. Acc Chem Res. 2019;52(8):2332-9. https://doi.org/10.1021/acs.accounts.9b00273.

116. Kobayashi H, Furusawa A, Rosenberg A, Choyke PL. Near-infrared photoimmunotherapy of cancer: A new approach that kills cancer cells and enhances anti-cancer host immunity. Int Immunol. 2020:dxaa037. https:// doi.org/10.1093/intimm/dxaa037.

117. Cognetti DM, Johnson JM, Curry JM, Mott F, Kochuparambil ST, McDonald D, et al. Results of a phase 2a, multicenter, open-label, study of RM-1929 photoimmunotherapy (PIT) in patients with locoregional, recurrent head and neck squamous cell carcinoma (rHNSCC). J Clin Oncol. 2019:37:6014. no. 15_suppl. https://doi.org/10.1200/JCO.2019.37.15_suppl.6014.

\section{Publisher's Note}

Springer Nature remains neutral with regard to jurisdictional claims in published maps and institutional affiliations. 